\title{
Ergonomic Design of Bent-Handled Culinary Spatula for Female Cook’s Stir-Frying Task
}

\author{
Swei-Pi Wu ${ }^{1 *}$, Chien-Hsin Yang ${ }^{2}$, Chia-Hui Lin ${ }^{3}$ and Pai-Kang Pai ${ }^{1}$
}

${ }^{1}$ Ergonomics Research laboratory, Department of Industrial Engineering and Information on Management, Huafan University, Taiwan

${ }^{2}$ Department of Industrial Engineering and Management, Overseas Chinese University, Taiwan

${ }^{3}$ Department of Design Marketing, Tung Fang Design Institute, Taiwan

\begin{abstract}
This study evaluates how different culinary spatula (turning shovel) designs affect cooking performance during stir-frying. A straight-handled spatula $\left(0^{\circ}\right)$ and three bent-handled spatulas $\left(15^{\circ}, 30^{\circ}\right.$ and $\left.45^{\circ}\right)$ were evaluated across two handle length levels $(25 \mathrm{~cm}$ and $30 \mathrm{~cm})$. The criterion measures included food-frying efficiency, work posture and subjective rating of perceived discomfort. In a laboratory experiment, 13 female participants were required to simulate a food-frying task with each spatula. The participants ranked their preference after all tests had been completed. The results showed that both the angle of the bent handle and the handle length significantly affected the four criteria. Bent-handled spatulas could effectively reduce palmar flexion/ extension and radial/ulnar deviation, and increase food-frying efficiency, comfort and subjective preference. In general, a benthandled spatula with a $15^{\circ}$ angle and a handle $25 \mathrm{~cm}$ in length was the best for female cooks stir-frying task.
\end{abstract}

Keywords: Ergonomic design; Cook; Culinary spatula; Bent handle; Catering industry

\section{Introduction}

Occupational safety and health problems are important issues in the catering industry. According to Labor Department [1] statistics, catering remains an industry in Hong Kong with a high rate of workrelated accidents. In 1999, 58841 cases of occupational injury and death were recorded, of which 12549 cases occurred in the catering industry, representing $21 \%$ of the total number. Further, the Occupation safety and Health Council conducted a survey to examine the occupational safety and health problems faced by kitchen workers in Chinese restaurants. A total of 471 cooks in 159 Chinese restaurants were interviewed. The results showed that $80 \%$ of the cooks had experienced work-related injuries and over $60 \%$ of the cooks had asked for sick leave because of accidents at work.

Work-related musculoskeletal disorders (WMSDs) are very common for cooks in the catering industry. The Occupation safety and Health Council found the most common work-related disease was musculoskeletal disease $(41.2 \%)$, and more than $50 \%$ of cooks suffered from musculoskeletal diseases in the past 12 months. Gigstad [2] confirmed $57 \%$ of the cooks reported pain in their hands and wrists with the most common ailment being numbness (73\%) in unspecified body parts. Chyuan et al. [3] found that $84 \%$ of participants reported experience with WMSDs in the previous month, with a high prevalence rate over the shoulder (58\%), neck (54\%), lower back/waist (53\%) and finger/waist $(46.5 \%)$ among hotel restaurant workers in Taiwan. Similarly, Chyuan $[4,5]$ revealed a high prevalence of WMSDs over the shoulder (41.1\%), hands/wrists (38.2\%) and lower back (40.1\%) among foodservice workers in Taiwan.

Clearly, work-related musculoskeletal disorders are very common in the catering industry, especially among cooks. Based upon previous studies [1-4] improper manual handling of loads, improper work posture and awkward movements, prolonged repetitive movement, forceful hand exertion, improper workstations, prolonged standing, unsuitable tools and equipment are the workplace risk factors for
WMSDs. For example, food frying is one of the most common cooking activities for cooks in Chinese restaurants or kitchens. When frying food, the cook normally stands still with the preferred hand grasping the handle of the culinary spatula (turning shovel) and the other hand grasping the handle of the wok. To quickly and evenly disperse the food being heated in the wok, the cook usually stirs the food with a spatula or flips the food in the wok during stir frying. The food-frying task, involving rapid and repetitive hand, arm and wrist movements combined with a static load in the upper arm and shoulder when flipping the wok and tossing the ingredients, is likely to increase the risk for upper extremity musculoskeletal disorders [1,6-9]. A conventional straight-handled spatula is extensively used by cooks [6] examined the effects of spatula lift angle on cooking performance and subjective ratings. Their results showed that lift angle significantly affected both performance and subjective rating [6] found the optimum lift angle to be $25^{\circ}$ [9] further studied the handle length and spatula lift angle effects on cooking performance and subjective ratings. Their results showed a spatula with a $25 \mathrm{~cm}$ handle and a lift angle of $25^{\circ}$ as the best. However, the aforementioned study did not consider the effect of a bent handle. According to previous studies [10-14] tools with bent handles could effectively reduce unnatural postures and repetitive forceful exertion of hand/wrist movements. Therefore, this work conducted experiments to evaluate the effects of the conventional straight-handled spatula and ergonomic bent-handled spatulas of different lengths on food-frying efficiency, work posture and subjective rating. It is hoped that the results can serve as a reference for designing a novel spatula that decreases the awkward posture and discomfort of female cooks during food-frying.

*Corresonding author: Swei-Pi Wu, Ergonomics Research laboratory, Department of Industrial Engineering and Information on Management, Huafan University, Taiwan, Tel: 886-2-26632102; Fax: 886-2-26631119; E-mail: spwu@huafan.hfu.edu.tw

Received May 23, 2015; Accepted June 15, 2015; Published June 22, 2015

Citation: Wu SP, Yang CH, Lin CH, Pai PK (2015) Ergonomic Design of BentHandled Culinary Spatula for Female Cook's Stir-Frying Task. J Food Process Technol 6: 476. doi:10.4172/2157-7110.1000476

Copyright: $\odot 2015$ Wu SP, et al. This is an open-access article distributed unde the terms of the Creative Commons Attribution License, which permits unrestricted use, distribution, and reproduction in any medium, provided the original author and source are credited. 


\section{Methods}

\section{Participants}

Thirteen female participants were recruited for this experiment. They were paid for their participation in this study. The mean age and height were $19.6(\mathrm{SD}=0.87)$ years and $161.2(\mathrm{SD}=5.37) \mathrm{cm}$, respectively. The participants were right-handed and had at least one year of cooking experience in Chinese Cuisine with no history of musculoskeletal injuries. The participants were familiarized with the experimental purpose and procedures before the experimental data were collected.

\section{Apparatus}

A twin-axis, flexible electro-goniometer (XM65; Penny \& Giles Ltd, Blackwood, Gwent, UK) attached to the dorsal surface of the third metacarpal bone and the forearm was employed to collect the wrist angle data in the flexion/extension (F/E) and ulnar/radial (U/R) planes $[15,16]$. The electrogonimeter was calibrated by placing the subject's wrist and forearm in a neutral $\mathrm{F} / \mathrm{E}$ and $\mathrm{R} / \mathrm{U}$ position and recording the zero positions by pushing a button on the electrogonimerer's logger as specified by Johnson and Johnson [17].

A convex-bottomed wok (380 $\mathrm{mm}$ diameter and $110 \mathrm{~mm}$ deep) and eight culinary spatulas were purchased from a hardware store. According to Hsu et al. [6] and Wu and Hsieh [9], the spatula lift angle was set to $25^{\circ}$. The handle bent angles were set to $0^{\circ}, 15^{\circ}, 30^{\circ}$ and $45^{\circ}$. To test the handle length effect, two handle lengths $(25 \mathrm{~cm}$ and $30 \mathrm{~cm})$ were evaluated. Adhering with magnet, the spatula weight with shorter handles was made equal to that of the spatula with the longest handle to minimize the weight effect. The center of gravity locations were set at $20 \mathrm{~cm}$ and $25 \mathrm{~cm}$ apart from the handle top for the $25 \mathrm{~cm}$ and 30 $\mathrm{cm}$ handles, respectively. To prevent participants from touching the edge of a hot wok, the bent-handled spatulas were designed to curve upward. Figure 1 depicts the shape and size of the spatulas used in this experiment.

\section{Experimental design}

This experiment used a two-factor, within-subject design. The main factors were the bent angle of the handle $\left(0^{\circ}, 15^{\circ}, 30^{\circ}\right.$ and $\left.45^{\circ}\right)$ and handle length $(25 \mathrm{~cm}$ and $30 \mathrm{~cm})$. The spatula with a $0^{\circ}$ bent angle is the conventional straight-handled spatula. The criterion measures included objective measures for food-frying efficiency and work posture and a subjective rating for perceived discomfort. Food-frying efficiency was measured by the frequency of pronation and supination movement during food frying for two minutes. Each participant was asked to perform a food-frying task with eight combinations (four bent angles $\times$ two handle lengths) in a random order and repeat this with a counter balance method to eliminate the learning effect.

After the participants completed 16 trials, the eight spatulas were arranged and the participants assessed their subjective preference for each spatula. The height of the working platform was adjusted for each participant according to their knuckle height. The experimental setup is shown in Figure 2.

\section{Experimental procedure}

Each participant filled out an Informed Consent Form and received a verbal explanation of the experimental purpose and procedure. The participants were allotted to $1 \mathrm{hr}$ training sessions to practice the foodfrying task until they were familiar with the experimental procedure, using eight culinary spatulas in a random order.

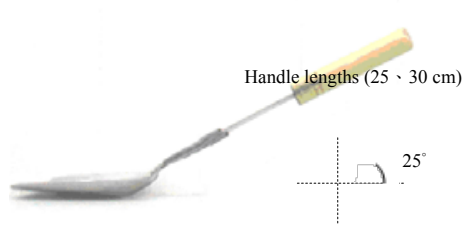

Bent angle $=0^{\circ}$

(a) straight-handled spatula

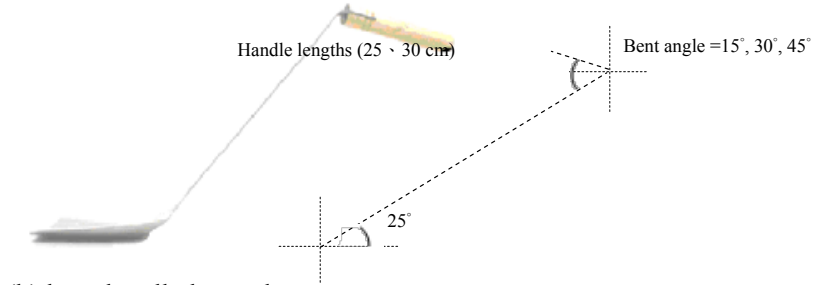

(b) bent-handled spatula

Figure 1: The experimental culinary spatulas used in the study.
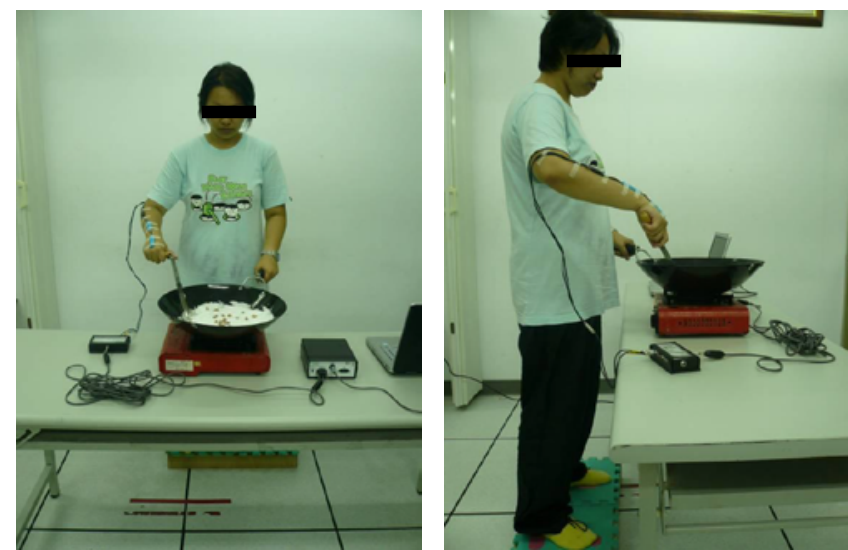

Figure 2: The experimental set-up.

After the training session the participants formally participated in the food-frying experiment. Each participant was required to first read the instructions and then perform a $10 \mathrm{~min}$ warm-up exercise before the test.

After the warm-up exercise, the electrogoniometer was placed on the participant to measure their work posture.

The food-frying task involved the participant standing still naturally, grasping the handle of the spatula with the preferred hand and putting the blade into the center of the wok. Concurrently, he or she had to grasp the wok handle with the other hand. When the test began the participant used the spatula to stir foods ( $1500 \mathrm{~g}$ salt and $30 \mathrm{~g}$ peanut) across the wok along three predetermined paths in a counter-clockwise order, performing pronation and supination movements frying the foods cyclically in each path $[6,9]$. After 2 min the participant placed the blade back into the center of the wok. The pronation and supination movement frequencies were recorded as the food-frying efficiency.

To minimize emotional influence the experimenters kept their voice tone neutral and avoided emotional appeals, onlooker interference, or competition. Note that the frying speeds of the participants were not 
controlled. However, it was assumed that the frequency of frying food would be affected by the experimental conditions. After the participant finished the frying task with a given spatula, he/she was asked to rate a subjective scale of perceived discomfort. The scale contained five adjective pairs: wrist aching vs. wrist not aching, arm aching vs. arm not aching, shoulder aching vs. shoulder not aching, gripping easily vs. gripping with difficulty, and exerting easily vs. exerting with difficulty. Each pair had an unmarked scale from 1 to 9. The higher the scores on the scale, the less discomfort the participant felt, or the better the design was.

The order of experimentation was randomized and repeated with counterbalance to minimize the learning effect. A $5 \mathrm{~min}$ rest period was provided when switching between spatulas. The participant was requested to rank his/her preference from 1 (favorable) to 8 (unfavorable) for the eight experimental spatulas.

\section{Statistical analysis}

The independent variables for this study were the bent angle and handle length. The dependent variables included food-frying efficiency, $\mathrm{F} / \mathrm{E}$ and $\mathrm{U} / \mathrm{R}$ angle of wrist, scores of subjective rating and preference ranking. Analysis of variance for food-frying efficiency, wrist angle and subjective rating were conducted to test the bent angle and handle length effects. The subjective ranking scores among the eight different spatulas were assumed as interval values and tested by ANOVA. For each significant main ANOVA effect, post hoc analysis was performed using Duncan's multiple range tests. A significance level of 0.05 was adopted.

\section{Results}

Table 1 summarizes the results of the analysis of variance (ANOVA) and Duncan's multiple range test for all criterion measures.

\section{Food-frying efficiency}

Effect of bent angle: The ANOVA on the food-frying efficiency data in Table 1 reveals that bent angle had a significant effect on food-frying efficiency $(\mathrm{F}=2.83, \mathrm{P}<0.05)$. Subsequent Duncan test Table 1 indicated that the efficiency produced by the $15^{\circ}$ angle was significantly superior to that by the $30^{\circ}$ and $45^{\circ}$ angles, but not significantly different from that by the $0^{\circ}$ angle. The $45^{\circ}$ angle exhibited the worst efficiency. Figure 3 displays the relationship between the bent angle and mean food-frying efficiency.
Effect of handle length: The ANOVA in Table 1 also indicates that handle length significantly affected food-frying efficiency $(\mathrm{F}=64.01$, $\mathrm{P}<0.001)$. Further examination of the Duncan test Table 1 reveals the efficiency produced by the $25 \mathrm{~cm}$ handle was significantly superior to that by the $30 \mathrm{~cm}$ handle. Figure 3 shows that the $25 \mathrm{~cm}$ handle was significantly superior to the $30 \mathrm{~cm}$ handle.

\section{Working posture}

Ulnar deviation: The ANOVA in Table 1 reveals the bent angle significantly affected ulnar deviation. The subsequent Duncan test in Table indicated the $45^{\circ}$ angle had the least ulnar deviation, followed by the $30^{\circ}$ angle with the $0^{\circ}$ and $15^{\circ}$ angles having the greatest ulnar deviation. Figure 4 illustrates the relationship between the bent angle and mean wrist angle for ulnar deviation.

Radial deviation: Both the bent angle and handle length significantly affected radial deviation (Table 1).

The Duncan test in Table 1 shows that the $30^{\circ}$ angle had the least radial deviation. It was not significantly different from the $45^{\circ}$ and $15^{\circ}$ angles, and the $0^{\circ}$ angle had the greatest radial deviation. The $25 \mathrm{~cm}$ handle had less radial deviation than the $30 \mathrm{~cm}$ handle. Figure 4 shows the bent angle and handle length effects on radial deviation.

Palmar flexion: The ANOVA in Table 1 indicates that both the bent angle and handle length significantly affected palmar flexion. The Duncan test in Table 1 reveals significant differences among the four angles. The $45^{\circ}$ angle had the least flexion, followed by the $30^{\circ}$ angle; the $15^{\circ}$ angle, with the $0^{\circ}$ angle having the greatest palmar flexion. In addition, palmar deviation by the $25 \mathrm{~cm}$ handle was significantly smaller than that for the $30 \mathrm{~cm}$ handle. Figure 4 shows the bent angle effect on palmar flexion.

Palmar extension (Dorsiflexion): The ANOVA in Table 1 shows that both the bent angle and handle length significantly affected palmar extension. Subsequent Duncan test Table 1 indicated that $15^{\circ}$ angle had the least palmar flexion compared with the $30^{\circ}$ and $45^{\circ}$ angles, but showed no significant difference from the $0^{\circ}$ angle. Figure 4 displays the difference in palmar extension for the various bent angles.

\section{Subjective rating}

Wrist, arm and shoulder aching: Both the bent angle and handle

\begin{tabular}{|c|c|c|c|c|c|c|c|c|c|c|c|c|}
\hline \multirow[b]{2}{*}{ Variables } & \multirow{2}{*}{$\begin{array}{c}\text { Food- } \\
\text { frying } \\
\text { efficiency }\end{array}$} & \multicolumn{4}{|c|}{ Wrist angle } & \multicolumn{6}{|c|}{ Subjective rating } & \multirow{2}{*}{$\begin{array}{c}\text { Subjective } \\
\text { ranking }\end{array}$} \\
\hline & & Ulnar deviation & $\begin{array}{c}\text { Radial } \\
\text { deviation }\end{array}$ & $\begin{array}{l}\text { Palmar } \\
\text { flexion }\end{array}$ & $\begin{array}{c}\text { Palmar } \\
\text { extension }\end{array}$ & Wrist & Arm & Shoulder & Grip & Exertion & Mean & \\
\hline Participants & $\star *$ & $* *$ & $* *$ & ** & ** & ** & ** & ** & ** & ** & ** & \\
\hline $\begin{array}{c}\text { Bent angle } \\
\text { (B) }\end{array}$ & * & $* *$ & $* *$ & ** & ** & $* *$ & ** & ** & ** & $* *$ & $* *$ & \\
\hline $\begin{array}{l}\text { Handle } \\
\text { length }(\mathrm{H})\end{array}$ & $* *$ & - & * & ** & $* *$ & ** & ** & ** & ** & ** & ** & \\
\hline $\mathrm{B} \times \mathrm{H}$ & ** & $* *$ & - & - & ** & - & - & - & - & - & - & \\
\hline \multirow{4}{*}{$\begin{array}{c}\text { Bent angle } \\
\left({ }^{\circ}\right)\end{array}$} & 15 & 45 & 30 & 45 & 15 & 15 & 15 & 15 & 15 & 15 & 15 & 15 \\
\hline & 0 & 30 & 45 & 30 & 0 & 30 & 30 & 30 & 30 & 30 & 30 & 0 \\
\hline & 30 & 0 & 15 & 15 & 30 & 0 & 0 & 0 & 0 & 0 & 0 & 30 \\
\hline & 45 & 15 & 0 & 0 & 45 & 45 & 45 & 45 & 45 & 45 & 45 & 45 \\
\hline \multirow{2}{*}{$\begin{array}{c}\text { Handle } \\
\text { length }(\mathrm{cm})\end{array}$} & 25 & 25 & 25 & 25 & 25 & 25 & 25 & 25 & 25 & 25 & 25 & 25 \\
\hline & 30 & 30 & 30 & 30 & 30 & 30 & 30 & 30 & 30 & 30 & 30 & 30 \\
\hline \multicolumn{13}{|l|}{ ** $: p<0.01$} \\
\hline \multicolumn{13}{|l|}{${ }^{*}: p<0.05$} \\
\hline \multicolumn{13}{|c|}{ - : non-significant difference } \\
\hline
\end{tabular}

Table 1: Summary ANOVA and Duncan test with food-frying efficiency, wrist angle and subjective rating as the dependent variables. 


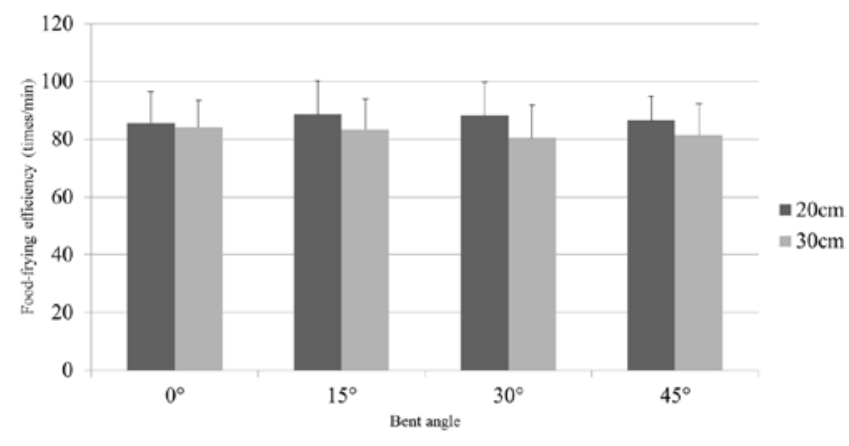

Figure 3: Bent angle effects on food-frying efficiency.

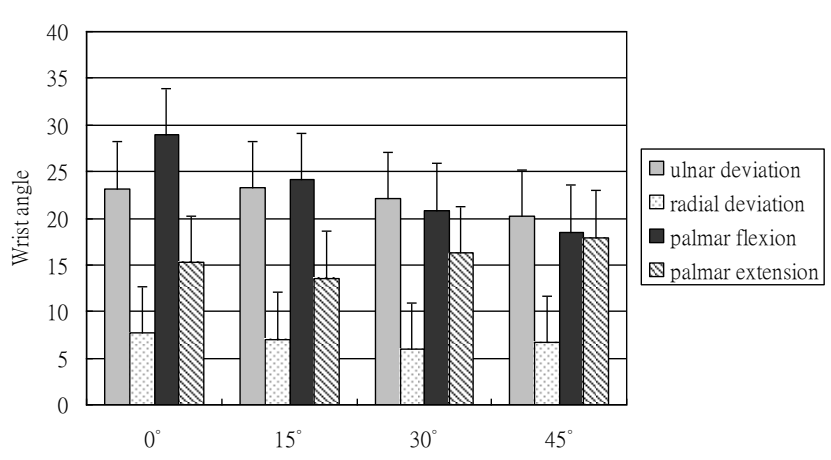

Figure 4: Bent angle effect on wrist angle.

length significantly affected subjective ratings of participants' wrist, arm and shoulder aching Table 1 and Figure 5. Significantly less ache was found in the wrist, arm and shoulder for the $15^{\circ}$ angle compared with the $30^{\circ}, 0^{\circ}$ and $45^{\circ}$ angles. The $45^{\circ}$ angle was reported to cause the most aches. Significantly fewer aches were found in the wrist, arm, and shoulder for the $25 \mathrm{~cm}$ handle compared with the $30 \mathrm{~cm}$ handle Table 1.

Ease of grip and exertion: The ANOVA result shows that both the bent angle and handle length significantly affected the subjective ratings of ease of grip and exertion Table 1 . Significantly greater ease of grip and exertion was reported for the $15^{\circ}$ angle compared with the $0^{\circ}, 30^{\circ}$ and $45^{\circ}$ angles. There was no difference reported between the $0^{\circ}$ and $30^{\circ}$ angles. Significantly less ease of grip and exertion was reported for the $45^{\circ}$ angle. Significantly greater ease of grip and exertion was reported for the $25 \mathrm{~cm}$ handle compared with the $30 \mathrm{~cm}$ handle Table 1.

\section{Subjective ranking}

The summary of the participants' subjective preference for the eight experimental spatulas reveals that the most preferred angle was $15^{\circ}$, followed by $0^{\circ}$ and $30^{\circ}$, with the $45^{\circ}$ angle being the least preferred. The most preferred handle length was $25 \mathrm{~cm}$, followed by $30 \mathrm{~cm}$. Further Duncan test analysis in Table 2 shows the eight types of spatulas can be divided into the following five groups in order of preference: (1) $25 \mathrm{~cm}$ $\times 15^{\circ}$, (2) $25 \mathrm{~cm} \times 30^{\circ}, 25 \mathrm{~cm} \times 0^{\circ}$ and $30 \mathrm{~cm} \times 15^{\circ}$, (3) $25 \mathrm{~cm} \times 45^{\circ}$ and $30 \mathrm{~cm} \times 0^{\circ}$, (4) $30 \mathrm{~cm} \times 30^{\circ}$, (5) $30 \mathrm{~cm} \times 45^{\circ}$.

\section{Discussion}

Table 3 summarizes the comprehensive comparison of the four criteria for evaluating the experimental spatulas. According to the Duncan's multiple range test in Table 1, the highest level in each

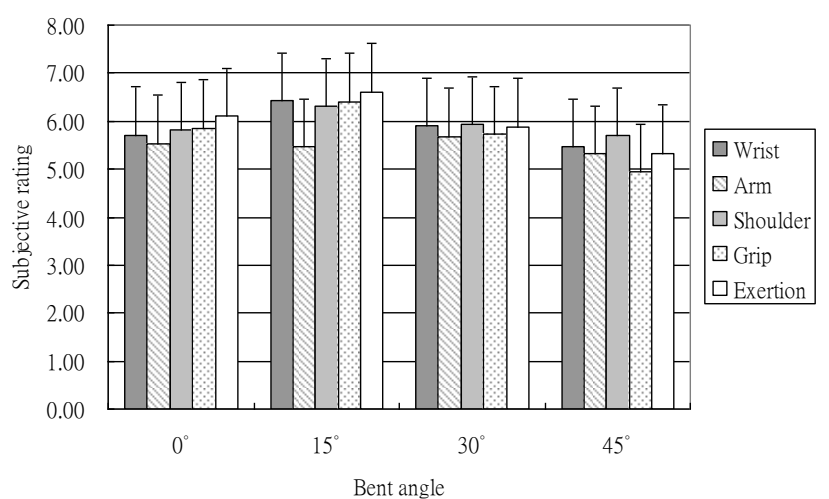

Figure 5: Bent angle effect on subjective rating.

\begin{tabular}{|c|c|c|c|c|c|c|}
\hline Treatments & Average & \multicolumn{5}{|c|}{ Group } \\
\hline $25 \mathrm{~cm} \times 15^{\circ}$ & 7.54 & A & & & & \\
\hline $25 \mathrm{~cm} \times 30^{\circ}$ & 5.92 & & B & & & \\
\hline $25 \mathrm{~cm} \times 0^{\circ}$ & 5.46 & & B & & & \\
\hline $30 \mathrm{~cm} \times 15^{\circ}$ & 5.31 & & B & & & \\
\hline $25 \mathrm{~cm} \times 45^{\circ}$ & 4.08 & & & C & & \\
\hline $30 \mathrm{~cm} \times 0^{\circ}$ & 3.92 & & & C & & \\
\hline $30 \mathrm{~cm} \times 30^{\circ}$ & 2.46 & & & & D & \\
\hline $30 \mathrm{~cm} \times 45^{\circ}$ & 1.31 & & & & & E \\
\hline
\end{tabular}

Table 2: The Duncan test of subjective preference.

\begin{tabular}{|c|c|c|c|c|c|c|c|}
\hline \multirow[b]{2}{*}{$\begin{array}{l}\text { Bent } \\
\text { angle }\end{array}$} & \multirow[b]{2}{*}{$0^{\circ}$} & $\begin{array}{c}\text { Food- } \\
\text { frying } \\
\text { efficiency }\end{array}$ & \multicolumn{2}{|c|}{$\begin{array}{l}\text { Working } \\
\text { posture }\end{array}$} & $\begin{array}{l}\text { Subjective } \\
\text { rating }\end{array}$ & $\begin{array}{l}\text { Subjective } \\
\text { preference }\end{array}$ & Tot \\
\hline & & 0 & -1 & & 0 & 0 & -1 \\
\hline & $15^{\circ}$ & +1 & to & & +1 & +1 & +3 \\
\hline & $30^{\circ}$ & 0 & 0 & & 0 & 0 & 0 \\
\hline & $45^{\circ}$ & -1 & +1 & & -1 & -1 & -2 \\
\hline \multirow[t]{2}{*}{$\begin{array}{l}\text { Handle } \\
\text { length }\end{array}$} & $\begin{array}{l}25 \\
\mathrm{~cm}\end{array}$ & +1 & +1 & & +1 & +1 & +4 \\
\hline & $\begin{array}{l}30 \\
\mathrm{~cm}\end{array}$ & -1 & -1 & & -1 & -1 & -4 \\
\hline
\end{tabular}

Note: The highest level of Duncan's multiple range test, the spatula(s) obtains +1 .

The lowest level of Duncan's multiple range test, the spatula(s) obtains -1 .

Table 3: Comprehensive comparison of the four criteria used to evaluate the spatulas.

criterion obtained a score of +1 , while the lowest level obtained -1 . The scores were summed to determine the quality level of the spatula. Each of the criteria had the same weight of importance and the higher the score, the better the quality a spatula has [12].

\section{Effect of bent angle}

Table 3 shows the $15^{\circ}$ angle was the optimum bent angle for three criteria, namely food-frying efficiency, subjective rating and subjective preference. The $45^{\circ}$ angle was the best angle for the work posture criteria. In general, the $15^{\circ}$ angle was the best, followed by the $30^{\circ}$ and $0^{\circ}$ angles, with the $45^{\circ}$ angle being the worst.

This study confirmed that bent-handled spatulas $\left(15^{\circ}, 30^{\circ}\right.$ and $45^{\circ}$ bent angles) could effectively decrease the wrist angle, while the conventional straight- handled spatulas $\left(0^{\circ}\right.$ angle $)$ caused the greatest wrist angle, especially for ulnar deviation and palmar flexion. Carey 
and Gallwey [18] reported extreme flexion caused greater discomfort than other simple types of deviation and the combination of palmar flexion and ulnar deviation resulted in more discomfort than other types of combined deviation. Therefore, the three bent- handled spatulas resulted in better posture than the conventional spatula according to the work posture criterion. However, among the three bent-handled spatulas, the bent-handled spatula with a $45^{\circ}$ angle was worse than the other two bent-handled spatulas in terms of food-frying efficiency, subjective rating and subjective ranking. According to our observation, the greater the bent angle, the lower the elbow position will be. To perform pronation and supination movements when frying foods in the wok, the participants must raise their elbow to manipulate the spatula. Such uncoordinated postures and movements may cause difficulty for the participants in holding and exerting the spatula, and in turn lead to low task efficiency, subjective rating and preference. In other words, bent-handled spatulas were definitely better than the straight-handled spatula for food-frying in the wok. The $15^{\circ}$-benthandled spatula was the best compared with the other bent-handled $\left(30^{\circ}\right.$ and $\left.45^{\circ}\right)$ and straight-handled spatulas.

\section{Effect of handle length}

As shown in Table 3, $25 \mathrm{~cm}$ was the optimum handle length for all four criteria. From observations of hand operation when frying food, it was found the longer the handle length, the higher the required grasping position. Thus, to reduce the wrist flexion angle, the participant raises their elbow to maintain a straight wrist, thus reducing foodfrying deficiency. The raised elbow position was also uncomfortable. Therefore, the $30 \mathrm{~cm}$ handle was worse in terms of frying efficiency as well as for work posture, subjective rating and subjective preference. This result agrees with the findings of $\mathrm{Wu}$ and Hsieh [8]

\section{Effect of interaction}

The ANOVA in Table 1 shows the interaction effect of both the bent angle and handle length on food-frying efficiency was significant $(\mathrm{F}=6.33, \mathrm{P}<0.001)$. As seen in Figure 3, the efficiency produced by the smaller bent angles $\left(0^{\circ}, 15^{\circ}\right)$ was superior to the larger bent angles $\left(30^{\circ}\right.$, $45^{\circ}$ ) for the $30 \mathrm{~cm}$ handle. From observations of hand operations when frying food, it was found that when participants used a longer spatula with larger bent angles, he or she had to grasp the handle at a higher position. To reduce the wrist extension angle, the participants raised their elbow to fry food, thus reducing food-frying performance. This finding differs from that obtained for the $25 \mathrm{~cm}$ handle.

\section{Conclusions}

The effect of the bent angle and handle length on food-frying efficiency, work posture, subjective rating and subjective ranking was examined in this study. Through comprehensive analysis and discussion we draw the following conclusions.

The bent angle significantly affected food-frying efficiency, work posture, subjective rating, and subjective ranking. The bent-handled spatula with a $15^{\circ}$ angle was the best.

Second, handle length also significantly affected food-frying efficiency, work posture, subjective rating, and subjective ranking. The $25 \mathrm{~cm}$ handle was better than the $30 \mathrm{~cm}$ handle.

Third, an ergonomic bent-handled spatula with a $15^{\circ}$ angle and a handle of $25 \mathrm{~cm}$ handle long was the optimum within our experimental investigation for female cooks when frying food.
Finally, we recommend the bent-handled spatula (with an angle ranging from $15^{\circ}$ to $30^{\circ}$ ) replace the conventional straight-handled spatula.

\section{References}

1. Labor Department (2006) Hints on prevention of musculoskeletal disorders Government Logistics Department.

2. Gigstad J (2002) Ergonomic analysis of production cooks at XYZ high school. University of Wisconsin-Stout, United States.

3. Chyuan JY, Du CL, Yeh WY, Li CY (2004) Musculo-skeletal disorders in hote restaurant workers. Occup Med-Oxf 54: 55-57.

4. Occupational Safety and Health Council (2000) Survey on occupational safety and health conditions of kitchen work in Chinese restaurants.

5. Chyuan JY (2007) Ergonomic assessment of musculoskeletal discomfort among commissary foodservice workers in Taiwan. Journal of Foodservice Business Research 10: 73-86.

6. Hsu SH, Wu SP, Peng Y (1994) The optimum lift angle for the culinary spatula (turning shovel). Ergonomics 37: 325-332.

7. Okunribido OO, Haslegrave CM (1999) Effect of handle design for cylinder trolleys. ApplErgon 30: 407-19.

8. Buckle PW, Devereux JJ (2002) The nature of work-related neck and uppe limb musculoskeletal disorder. ApplErgon 33: 207-17.

9. Wu SP, Hsieh CS (2002) Ergonomics study on the handle length and lift angle for the culinary spatula. ApplErgon 33: 493-501.

10. Armstrong TJ, Foulke JA, Joseph BS, Goldstein SA (1982) Investigation of cumulative trauma disorders in a poultry processing plant. J Occup Environ Hyg 43: 103-16.

11. Konz S (1986) Bent handle hammer. Hum Factors 28: 317-323.

12. Lewis WG, Narayan CV (1993) Design and sizing of ergonomic handles fo hand tools. ApplErgon 24: 351-356.

13. Hsu SH, Chen YH (2000) Evaluation of bent-handled files. Int J IndErgon 25 1-10.

14. Li KW (2002) Ergonomic design and evaluation of wire-trying hand tools. Int $J$ IndErgon 30: 149-161.

15. Roquelaure Y, D'Espagnac F, Deleamarre Y, Penneau-Fontbonne D (2003) Biomechanical assessment of new hand-powered pruning sheets. ApplErgon 35: $179-82$.

16. Roquelaure Y, Dano C Dussolier G, Fanello S, Penneau-Fontbonne D (2002) Biomechanical stains on the hand-wrist system during grapevine pruning. Int Arch Occup Environ Health 75: 591-95.

17. Johnson P, Johnson PW (2001) Comparison of measurement accuracy between two types of wrist goniometer systems. ApplErgon 32: 599-607.

18. Carey EJ, Gallwey TJ (2002) Effects of wrist posture, pace and exertion on discomfort. Int J IndErgon 29: 85-94. 